\title{
Proposta de nova versão ao jogo Hemotion
}

\author{
Antonio A. Pereira Junior ${ }^{1}$, Marcos A. Francisco Borges ${ }^{2}$ \\ ${ }^{1}$ Faculdade de Tecnologia - Universidade Estadual de Campinas (FT/UNICAMP) \\ Caixa Postal 456 - 13484-332 - Limeira - SP - Brasil \\ ${ }^{2}$ Laboratório de Informática, Aprendizagem e Gestão/ FT (LIAG) \\ Caixa Postal 456 - 13484-332 - Limeira - SP - Brasil \\ antonioalbertojunior95@gmail.com, marcos.borges@ft.unicamp.br
}

\begin{abstract}
This article presents a proposal for a new version of the Hemotion. The game is used by children with hemophilia and requires changes. This work intends to evaluate the technical options to perform a conversion of the game to a new platform, taking into consideration the requirements acquired and the exploitation of the previous version .
\end{abstract}

Resumo. Este artigo apresenta uma proposta de nova versão ao jogo Hemotion. O jogo é usado por crianças com hemofilia e requer mudanças. Este trabalho pretende avaliar as possíveis opções técnicas de realizar a conversão do jogo para uma nova plataforma, levando em consideração os requisitos levantados e o maior aproveitamento da versão anterior.

\section{Introdução}

O Hemotion [Matsunaga and Borges 2012; Matsunaga, Borges and Moraes 2013; Matsunaga et al. 2012] é um jogo educativo para crianças hemofílicas que discute como as crianças devem agir diante das adversidades do dia a dia. O principal personagem do Hemotion é o João Ventura, uma criança do interior do Brasil que tem hemofilia. $\mathrm{O}$ jogador define as escolhas que o personagem João fará no decorrer do jogo. O objetivo do jogo é acompanhar o dia-dia do João durante uma semana e entender como as escolhas que ele faz influenciam na vida de alguém que é portador da hemofilia.

Este artigo descreve uma pesquisa feita para identificar as possíveis opções técnicas para realizar a conversão do jogo para uma nova plataforma, desenvolvendo um protótipo da nova versão na plataforma de desenvolvimento estudada. O jogo já é usado por crianças com hemofilia. Mas a versão anterior precisava de melhorias. Havia, por exemplo, a solicitação para que o jogo fosse internacionalizado, para que pudesse ser usado em países de línguas espanhola ou inglesa, por exemplo. Mas a plataforma Adobe Flash [Flash 2017], na qual o jogo originalmente foi desenvolvido, está sendo descontinuada. Este trabalho pretende avaliar as possíveis opções técnicas para converter o jogo para outra plataforma. 
VI Congresso Brasileiro de Informática na Educação (CBIE 2017)

Anais dos Workshops do VI Congresso Brasileiro de Informática na Educação (WCBIE 2017)

\section{Referencial Teórico}

Esta seção discorre sobre os referenciais teóricos para este artigo. A subseção 2.1 discorre sobre conceitos da hemofilia. A subseção 2.2 discorre sobre a metodologia de ensino "Learning by teaching".

\subsection{Hemofilia}

Hemofilia é uma doença genética, de herança recessiva ligada ao sexo. É consequência da falta ou defeito da produção das moléculas dos fatores VIII (hemofilia A) ou IX (hemofilia B) de coagulação. A doença é decorrente de alterações nos genes codificantes destes fatores localizados no braço longo do cromossomo sexual X [Nunes et al. 2009]. $\mathrm{Na}$ maioria dos casos, é transmitida a indivíduos do sexo masculino pela mãe portadora. Um indivíduo do sexo masculino com hemofilia poderá transmitir o gene da hemofilia para seus descendentes do sexo feminino, que serão portadoras não sintomáticas da hemofilia.

Em geral, as crianças hemofílicas não têm domínio sobre como a hemofilia, se não for tratada de forma adequada, pode ser prejudicial à saúde. É necessário, portanto, conscientizá-las sobre os cuidados necessários no dia-dia. O Hemotion é um exemplo de jogo para crianças com hemofilia, que tem como objetivo auxiliar as crianças a entender melhor como é a melhor forma de conviver com a doença.

\subsection{Learning by teaching}

A literatura educacional e a ciência cognitiva apoiam a ideia de que ensinar aos outros é uma forma poderosa de aprender [Biswas et al. 2005]. A metodologia Learning by teaching (LBT) tem como objetivo possibilitar que o aprendiz aprenda ensinando. Sendo assim, o aprendiz em um processo LBT, ao ensinar, pode vir a descobrir falhas no seu conhecimento prévio, construindo um conhecimento mais completo e correto.

O Hemotion é um exemplo de jogo baseado na metodologia LBT. Cada pessoa que jogar o Hemotion terá papel de tutor, pois deverá controlar as ações do personagem, baseando-se nas melhores escolhas para pessoas com hemofilia. O tutor deve aprender sobre conceitos de hemofilia para alcançar o sucesso do jogo.

\section{Materiais e Métodos}

Esta seção discorre sobre os matérias e métodos necessários para o desenvolvimento do jogo. A subseção 3.1 descreve as possíveis plataformas de desenvolvimento. A subseção 3.2 descreve o sistema de controle de versão utilizado no projeto do jogo. A subseção 3.3 descreve uma possível forma de realizar a internacionalização no jogo.

\subsection{Plataforma de desenvolvimento}

Durante a pesquisa foi necessário avaliar as possíveis plataformas para $\mathrm{o}$ desenvolvimento da nova versão do jogo. Para isso, foram pesquisadas engines e frameworks para o desenvolvimento. Em seguida, foi avaliado qual opção disponibilizava mais recursos para o maior aproveitamento do jogo legado.

O processo de escolha da plataforma de desenvolvimento foi baseado na quantidade de recursos que a plataforma disponibilizava. Os recursos avaliados foram: 
VI Congresso Brasileiro de Informática na Educação (CBIE 2017)

Anais dos Workshops do VI Congresso Brasileiro de Informática na Educação (WCBIE 2017)

linguagem de script, suporte a web, suporte 3D, plataforma de exportação, ambiente de desenvolvimento e licença. As plataformas analisadas durante o processo de escolha foram: Canvas Engine, Construct 2, Unity, Allegro, Turbulenz, Panda.js, Cocos 2d-X, Phaser, Enchant.js. A Figura 1 a seguir ilustra a quantidade de recursos por plataforma.

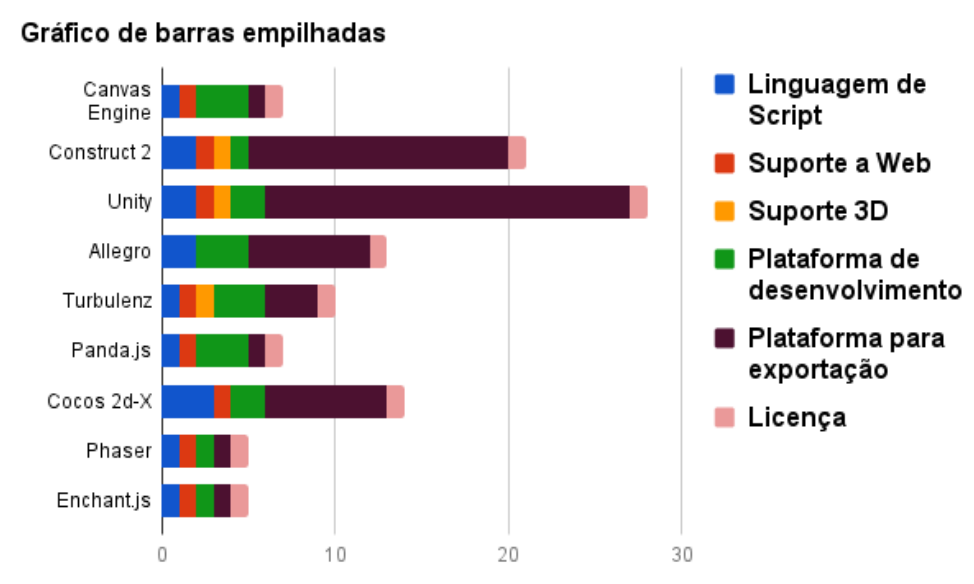

Figura 1. Gráfico ilustrando quantidade de recursos por plataforma.

Posteriormente foi verificado que a plataforma de desenvolvimento Unity disponibilizava todos os recursos necessários para o desenvolvimento do jogo. Com base neste processo a engine foi escolhida para substituir a plataforma Flash.

\subsection{Controle de Versão}

Sistemas de controle de versão são uma solução para armazenamento e controle de múltiplas versões de informações em formato digital, como, por exemplo, códigos, documentos ou modelos. Esses sistemas são comumente usados para facilitar a sincronização entre diversos desenvolvedores, acompanhando a evolução do produto e fornecendo backup em caso de perda de dados [Hallmans et al. 2016].

O TortoiseSVN [TortoiseSVN 2017] é uma ferramenta de código livre (open source), que fornece uma interface de usuário agradável e fácil para o sistema controlador de versão Subversion. Essa ferramenta armazena os dados em um repositório, sendo acessível a todos membros do time que estiver envolvido no projeto. Dentre as funcionalidades oferecidas pelo TortoiseSVN, pode-se citar: verificação de logs, visualização de histórico de alteração, bloqueio de arquivos, funcionalidades básicas de commit, update, delete e merge.

\subsection{JavaScript Object Notation}

O JavaScript Object Notation (JSON) é um formato de texto que facilita o intercâmbio de dados estruturados entre várias linguagens de programação. A notação JSON é definida por chaves e valores. Para isso, usa uma sintaxe de chaves, colchetes, colunas e vírgulas. Com a JSON é possível representar qualquer tipo de dado como matriz, vetor ou lista [ECMA 1999].

Ao adotar a convenção do JSON, estruturas de dados complexas podem ser facilmente intercambiadas entre linguagens de programação incompatíveis. Devido a 
VI Congresso Brasileiro de Informática na Educação (CBIE 2017)

Anais dos Workshops do VI Congresso Brasileiro de Informática na Educação (WCBIE 2017)

esta facilidade de trabalhar com a notação JSON, a internacionalização do jogo foi implementada com arquivos nessa notação.

\section{Construção do protótipo}

Após avaliar as engines e frameworks, foi verificado que a engine Unity [Unity 2017] disponibilizava todos os recursos necessários para o desenvolvimento do jogo. Sendo assim, a engine foi escolhida para o desenvolvimento e assim substituir a plataforma Flash. Para a apresentação dos resultados o projeto contemplou uma nova versão do Hemotion. O jogo foi disponibilizado na plataforma web, podendo ser acessado por qualquer pessoa, bastando acessar o site do laboratório ${ }^{1}$ no qual foi desenvolvido.

Para realizar a internacionalização no Hemotion, foram necessários arquivos de leitura do tipo JSON. No Hemotion, a notação JSON é utilizado para determinar áudios e textos. Na solução implementada no protótipo resultado, para disponibilizar o Hemotion em uma nova língua, basta criar um arquivo do tipo JSON para a configuração da língua desejada. A Figura 2 ilustra as telas da versão em inglês.

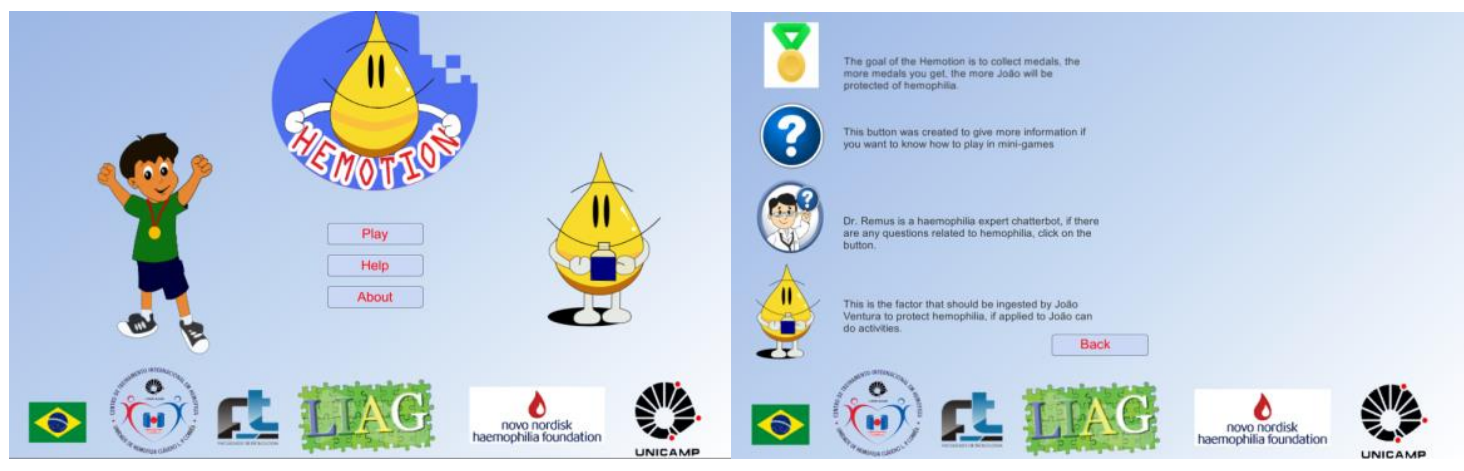

Figura 2. Telas ilustrando a internacionalização do Hemotion.

Um dos resultados obtidos no processo de desenvolvimento do Hemotion, foi devido ao desenvolvimento padronizado e organizado associado ao sistema de controle de versão. Além do controle de versão, foram gerados diagramas da metodologia UML[Booch, Rumbaugh and Jacobson 2006], como: diagrama de classe, diagrama de caso de uso, diagrama de componentes e diagrama de atividades. Esses diagramas são importantes para facilitar outras pesquisas relacionadas ao projeto do Hemotion.

\section{Considerações Finais}

Neste trabalho foi possível propor e disponibilizar uma nova versão do jogo Hemotion, em uma plataforma mais moderna. Este artigo descreveu como foi selecionada a nova plataforma de desenvolvimento para o Hemotion, com base nos recursos necessários. $\mathrm{O}$ protótipo apresentado disponibiliza todas as funcionalidades da versão anterior, corrige alguns erros e oferece uma funcionalidade para a internacionalização de forma simples, sem necessidade de codificação, utilizando a notação JSON. A nova versão do Hemotion foi desenvolvida em uma plataforma mais atual, que disponibiliza muitos recursos que podem ser agregados ao jogo em possíveis projeto futuros.

\footnotetext{
${ }^{1}$ http://www.ft.unicamp.br/liag/
} 
VI Congresso Brasileiro de Informática na Educação (CBIE 2017)

Anais dos Workshops do VI Congresso Brasileiro de Informática na Educação (WCBIE 2017)

Como projeto de continuidade, pode-se sugerir a implementação da internacionalização em várias línguas, exportação do jogo para a plataforma mobile, desenvolvimento de mini games, manutenção no chatterbot entre outros requisitos faltantes. Desta forma, esta nova versão do Hemotion poderá evoluir e motivar as crianças a jogarem com mais possibilidades de escolhas para que não seja um jogo monótono.

\section{Referências}

Adobe Flash (2017). http://www.adobe.com/br/products/animate, Junho.

Biswas, G., Leelawong, K., Schwartz, D., and Vye, N. (2005). "Learning by teaching: a new agent paradigm for educational software”. Applied Artificial Intelligence 19.3-4 (2005): 363-392.

Booch, G., Rumbaugh, J. and Jacobson, I. (2006). "UML: guia do usuário”. Elsevier Brasil.

European Computer Manufacturers Association ECMA. (1999) "ECMAScript Language Specification 3rd Edition", http://www.ecmainternational.org/publications/files/ecma-st/ECMA-262.pdf, Dezembro.

Lednicki, L., Sapienza, G., Johansson, M. E., Seceleanu, T., and Hallmans, D. (2016, June). "Integrating version control in a standardized service-oriented tool chain". In Computer Software and Applications Conference (COMPSAC), 2016 IEEE 40th Annual (Vol. 1, pp. 323-328). IEEE.

Matsunaga, R. M. and Borges, M. A. F. (2012). "Developing a Serious Game for childreen with hemophilia". IADIS Multi Conference on Computer Science and Information Systems 2012, 2012, Lisboa. Proceedings of the IADIS International Conference Game and Entertainment Technologies. p. 77-80.

Matsunaga. R. M., Borges, M.A.F., Moraes, R. L. O. (2013). "Desenvolvimento de um jogo educativo para crianças com hemofilia”. Dissertação de Mestrado. Faculdade de Tecnologia, Universidade Estadual de Campinas, Limeira, SP.

Matsunaga, R. M., Matta, M. A., Ozelo, M. C., Padula, L. L., Pereira, E. D. S., and Borges, M. A. (2012). "Apresentação de um jogo educativo para crianças com hemofilia”. In: Anais dos Workshops do Congresso Brasileiro de Informática na Educação (Vol. 1, No. 1).

Nunes, A. A., Rodrigues, B. S., Soares, E. M., Soares, S. and Miranzi, S. S. (2009). "Qualidade de vida de pacientes hemofílicos acompanhados em ambulatório de hematologia”. Revista Brasileira de Hematologia e Hemoterapia.

Tortoise SVN. (2017). https://tortoisesvn.net/, Junho.

Unity 3D. (2017). https://unity3d.com/pt/, Junho. 